\title{
SIMULASI BIOMASSA AKAR, BATANG, DAUN DAN BIJI JAGUNG HIBRIDA PADA BEBERAPA PERLAKUAN PEMBERIAN NITROGEN
}

\section{SIMULATIONS BIOMASS OF ROOTS, STEMS, LEAVES AND SEEDS OF HIBRYD MAIZE IN SOME OF THE NITROGEN TREATMENTS}

\section{Frangky J. Paat}

Program Studi Agroekoteknologi, Fakultas Pertanian Universitas Sam Ratulangi Manado _ 95115 e-mail : frangky.paat@yahoo.com, frangkyip@gmail.com.

\section{ABSTRACT}

This study was aiming to assess growth of roots, stems, leaves and seeds of hybrid corn at different application of nitrogen using a simulation model approach. The research was conducted at the experimental garden in the village of Kakas Tountimomor Minahasa Region. The result showed that after 49 days of planting, optimum root biomass was $1050 \mathrm{~kg} / \mathrm{ha}$. Application of fertilization $92 \mathrm{~kg} /$ ha produced the highest production which was $43.8 \mathrm{~kg} / \mathrm{ha}$. Field measurement showed that application of fertilization $92 \mathrm{~kg} /$ ha resulted steem biomass $170.6 \mathrm{~kg} / \mathrm{ha}$. Simulation model revealed that stem biomass at the age of 70 HST allocated the highest photosyntate which was $1300 \mathrm{~kg} / \mathrm{ha}$. The highest leaves biomass production was detected at the level of nitrogen fertilization $92 \mathrm{~kg} / \mathrm{ha}$ resulting total production of $53.2 \mathrm{~kg} / \mathrm{ha}$. Optimalitation of biomass allocated to leaves until the flowering phase was 49 days after planting producing $3000 \mathrm{~kg} / \mathrm{ha}$. Field measurements for the highest seed biomass production was $54.9 \mathrm{~kg} / \mathrm{ha}$ accounted by $92 \mathrm{~kg} \mathrm{~N} / \mathrm{ha}$. Simulation model of seed biomass showed that seed filling stage was in between anthesis stage $(75 \mathrm{HST})$ and physiological ripening (105 HST) accounted $4500 \mathrm{~kg} / \mathrm{ha}$.

Keywords : Simulation, Biomass, Roots, Steem, Leaves, Seeds, Maize, Nitrogen

\begin{abstract}
ABSTRAK
Penelitian ini bertujuan untuk mengidentifikasi pertumbuhan organ akar, batang, daun dan biji jagung hibrida dalam tiap-tiap perlakuan pemberian nitrogen melalui pendekatan model simulasi. Penelitian dilaksanakan dikebun percobaan di desa Tountimomor Kecamatan Kakas Kabupaten Minahasa. Hasil penelitian menunjukan bahwa model dapat mensimulasi titik optimum biomassa akar yaitu $1050 \mathrm{~kg} / \mathrm{ha}$ pada umur tanam 49 hari setelah tanam. Pemupukan nitrogen dengan taraf $92 \mathrm{~kg} / \mathrm{ha}$ menghasilkan produksi tertinggi $43.8 \mathrm{~kg} / \mathrm{ha}$. Hasil pengukuran lapang pada taraf pemupukan $92 \mathrm{~kg} \mathrm{~N} / \mathrm{ha}$ menghasilkan biomassa batang 170.6 $\mathrm{kg} / \mathrm{ha}$. Hasil simulasi model biomassa batang pada umur tanam $70 \mathrm{hst}$ menghasilkan alokasi proporsi fotosintesis tertinggi $1300 \mathrm{~kg} / \mathrm{ha}$. Hasil produksi biomassa daun tertinggi dihasilkan pada taraf pemupukan nitrogen $92 \mathrm{~kg} / \mathrm{ha}$ dengan total produksi $53.2 \mathrm{~kg} / \mathrm{ha}$. Optimalisasi proporsi biomassa yang dialokasikan ke daun sampai pada fase pembungaan yaitu 49 hari setelah tanam dengan bobot $3000 \mathrm{~kg} / \mathrm{ha}$. Hasil pengukuran lapang untuk produksi biomassa biji tertinggi $54.9 \mathrm{~kg} / \mathrm{ha}$ pada taraf pemupukan $92 \mathrm{~kg} \mathrm{~N} / \mathrm{ha}$. Hasil simulasi model biomassa biji menunjukkan bahwa setelah fase anthesis yaitu $73 \mathrm{hst}$, fase pengisian biji mulai berlangsung hingga matang fisiologis pada 105 hari setelah tanam dengan total biji $4500 \mathrm{~kg} / \mathrm{ha}$.
\end{abstract}

Kata kunci: Simulasi, Biomassa, Akar, Batang, Daun, Biji, Jagung, Nitrogen 


\section{PENDAHULUAN}

Produksi jagung nasional meningkat setiap tahun namun hingga kini belum mampu memenuhi kebutuhan domestik sekitar 11 juta ton/tahun, sehingga masih mengimpor dalam jumlah besar yaitu 1 juta ton. Sebagian besar kebutuhan jagung domestik untuk pakan dan industri pakan sekitar 57 persen, sisanya 34 persen untuk pangan dan 9 persen untuk kebutuhan industri lainnya. Diperkirakan pada tahun 2010 kebutuhan jagung nasional sekitar 21,17 juta ton (Anonim, 2007).

Total produksi jagung tahun 2006 mencapai 11,4 juta ton. Sulawesi merupakan daerah prioritas pengembangan jagung nasional dengan target produksi tahun 2010 sebanyak 5 juta ton dari hamparan pertanaman seluas 1 juta hektar (Apriyantono, 2007).

Kontribusi Sulawesi terhadap produksi jagung nasional saat ini sebanyak 12 persen dan diharapkan pada tahun 2007 Indonesia mencapai swasembada jagung. Melalui uraian tersebut dapat dilihat betapa pasar pangan sangat besar yang kita miliki dan diminati produsen pangan luar negeri, namun belum mencukupi kebutuhan pangan, pakan, dan industri nasional (Anonim, 2007).

Produktivitas yang dicapai sekitar 3 ton/ha, sedangkan potensi produksi ditingkatkan menjadi 67 ton/ha jagung pipilan kering. Penggunaan jagung hibrida masih rendah, sekitar 15 persen dari total areal tanam 3,3 juta hektar dan potensi areal dapat dikembangkan menjadi 7,5 hektar melalui pemanfaatan lahan yang sudah terbuka (Anonim, 2007).

Paruntu dan Palenewen (1990) menyatakan bahwa rendahnya produktivitas jagung disebabkan oleh penggunaan benih varietas lokal, penyiapan lahan kurang optimal, populasi tanaman terlalu tinggi atau jarak tanam kurang teratur, pemupukan kurang tepat, hama penyakit dan gulma belum terkendali dengan baik.

Pemupukan yang kurang tepat adalah salah satu faktor yang sangat penting dalam hubungannya dengan pertumbuhan dan produktivitas tanaman jagung (Walalangi, 2007). Nitrogen adalah salah satu unsur hara yang diperlukan untuk pertumbuhan dan perkembangan tanaman secara optimum. Nitrogen memegang peranan penting dalam proses biokimia tanaman, yaitu sebagai penyusun enzim, klorofil, asam nukleat, dinding sel dan berbagai komponen sel (Salisbury dan Ross, 1985).

Sebagian besar petani memberikan pupuk nitrogen hanya berupa taksiran mengenai tinggi rendahnya takaran pupuk nitrogen, karena jumlah takaran pupuk yang diberikan sebenarnya terlalu kecil dibandingkan dengan nitrogen total tanah yang diperkirakan sekitar 30 persen nitrogen yang diberikan hilang melalui pencucian dan denitrifikasi (Rogi, 1996).

Tinggi rendahnya takaran pupuk nitrogen yang diberikan sangat mempengaruhi nilai efisiensi fisiologis tanaman yang menyangkut proses anabolik dan katabolik dalam satu siklus hidup tanaman (Runtunuwu, 1990). Efisiensi pemupukan nitrogen merupakan ukuran kemampuan tanaman untuk memproduksi biomassa, dimana peningkatan kandungan nitrogen tanaman berhubungan dengan rasio antara jumlah nitrogen yang diserap tanaman dengan biomassanya (Walalangi, 2007).

Tujuan penelitian ini adalah mengidentifikasi biomassa organ akar, batang, daun dan biji jagung hibrida dalam tiap-tiap perlakuan pemberian nitrogen. Manfaat yang diperoleh melalui pendekatan model simulasi adalah sebagai alat analisis untuk memprediksi hasil dalam pengambilan keputusan.

\section{METODE PENELITIAN}

Penelitian ini dilaksanakan dalam bentuk percobaan lapang di Desa Tountimomor Kecamatan Kakas Kabupaten Minahasa. Pembuatan model di Laboratorium Modeling Tanaman Fakultas Pertanian Unsrat dan Laboratorium Modeling IPB Bogor. Uji tanah dilakukan di Laboratorium Departemen IImu Tanah dan Sumberdaya Lahan Fakultas Pertanian IPB. Penelitian ini dilaksanakan pada bulan Januari April 2007. Bahan dan alat yang akan digunakan antara lain: benih jagung varietas hibrida jaya 1 , pupuk urea, SP-36, KCL, herbisida, insektisida, plant catalyst, altimeter, termometer maksimumminimum, termometer tanah, psikrometer, penakar curah hujan, bajak traktor tangan, Leaf Area Meter. 
Penelitian ini dirancang menggunakan Rancangan Acak Lengkap dengan tiga taraf pemupukan yaitu: tanpa pemupukan (N0), pemupukan $46 \mathrm{~kg} \mathrm{~N} / \mathrm{ha}$ (N1), pemupukan $92 \mathrm{~kg} \mathrm{~N} / \mathrm{ha}$ (N2). Tiap perlakuan diulang sebanyak tiga kali. Selanjutnya dilakukan pembuatan model simulasi.

\section{Prosedur Lapang}

Persiapan tanah sebagai media tumbuh, di bajak dengan menggunakan traktor tangan disisir dua kali dengan tujuan menggemburkan tanah dan untuk memisahkan dari batu-batuan dan sampah organik lainnya. Petak percobaan dibuat ukuran $8 \times 3 \mathrm{~m}$. Benih ditanam dengan lubang tugal $3 \mathrm{~cm}$ tiap lubang tanam berisikan 1 benih. Jarak tanam $70 \times 20 \mathrm{~cm}$ dan kedalaman benih $4-5 \mathrm{~cm}$. Pengairan dilaksanakan sesuai kebutuhan tanaman, minimal 6 kali pengairan selama pertumbuhannya terutama pada saat pembungaan dan pengisian biji. Pemupukan nitrogen diberikan sebanyak tiga kali yaitu pada saat tanam, 30 hari setelah tanam dan 40 hari setelah tanam, dilanjutkan dengan penyemprotan Plant Catalyst konsentrasi 0,25 persen setara dengan 2,5 gr/l untuk mengoptimalkan serapan hara makro dan mikro yang dibutuhkan tanaman. Jarak lubang pemupukan dengan tanaman $5 \mathrm{~cm}$. Fosfor dan kalium sebagai pupuk dasar diberikan hanya satu kali pada saat tanam, dengan takaran $150 \mathrm{~kg} \mathrm{SP}$ 36 dan $75 \mathrm{~kg} \mathrm{KCl} / \mathrm{ha}$. Sampel tanah diambil pada kedalaman $20-30 \mathrm{~cm}$ dengan menggunakan bor tanah.

Pengamatan dilakukan pada setiap fase pertumbuhan dan perkembangan tanaman. Sampel bobot kering tanaman diambil setiap 14 hari untuk analisis tumbuh tanaman. Panen dilaksanakan saat tampilan rambut pada tongkol telah mengering.

\section{Prosedur Kerja Penyusunan Model}

Model simulasi yang dikembangkan (Handoko, 1996) bahwa berdasarkan tanggapan pertumbuhan tanaman terhadap nitrogen serta interaksinya. Prosedur penyusunan model meliputi: Formula Perhitungan Biomassa. Produksi biomassa potensial harian dihitung berdasarkan efisiensi penggunaan radiasi surya yang diintersepsi tajuk tanaman, hubungannya di berikan oleh Hukum Beer yaitu :

$$
I=Q 0(Q i-\sigma) ; \sigma=e^{-k} \text { LLD }
$$

Dimana:

Qo = Radiasi yang tiba diatas tajuk tanaman $\left(\mathrm{MJ} / \mathrm{m}^{2}\right)$

I = intensitas berkas cahaya

$\mathrm{e}=$ kapasitas benda memancarkan atau menyerap radiasi. (e daun $=0,95$ )

Qi = Radiasi yang diserap $\left(\mathrm{MJ} / \mathrm{m}^{2}\right)$

$\sigma=$ Proporsi radiasi surya yang ditransmisikan oleh tajuk tanaman

$\mathrm{k}=$ Koefisien pemadaman

\section{ILD = Indeks Luas Daun}

Produksi biomassa potensial dihitung berdasarkan hasil kali antara efisiensi penggunaan radiasi surya $(\varepsilon)$ dengan radiasi intersepsi (Qi). Nilai efisiensi penggunaan radiasi di tentukan sebesar $\varepsilon=$ $0.0014 \mathrm{~kg} \mathrm{MJ}^{-1}$

\section{$B b=\varepsilon Q i=\varepsilon\left(1-e^{-k ~ I L D}\right) Q_{0}$}

Dimana:

$\mathrm{Bb}=$ Produksi biomassa potensial $\left(\mathrm{kg} \mathrm{ha}^{-1} \mathrm{~d}^{-1}\right)$

$\mathrm{E}=$ efisiensi penggunaan radiasi $\left(\mathrm{kg} \mathrm{MJ}^{-1}\right)$.

Produksi biomassa potensial tersebut menganggap ketersediaan air bukan merupakan faktor pembatas. Produksi biomassa aktual dihitung dengan mempertimbangkan ketersediaan air, yang dihitung berdasarkan nisbah antara hantaran stomata aktual (фpa) dengan nilai hantaran stomata maksimumnya (фm). Berikut adalah perhitungan faktor ketersediaan air (fw) dan produksi biomassa aktual $(\mathrm{Ba})$.

$\mathrm{Fw}=\mathrm{pa} / \mathrm{cpm}$

$B a=f w \cdot B b$

Ba dalam $\mathrm{kg}$ ha ${ }^{1} \mathrm{~d}^{1}$. Hantaran stomata aktual (фa, mm s-1) dihitung dari transpirasi harian. Transpirasi aktual dihitung dari sub model air dan defisit tekanan uap air. Hantaran stomata maksimum ( radiasi surya bersih (Qsn).

pm $=0.5+0.020$ Qsn

Dimana: Qsn dalam $\left(\mathrm{Wm}^{2}\right)$. 
Kehilangan bahan kering dari organ vegetatif (daun, batang dan akar) selama pemunculan kecambah sampai pembuangan melalui proses respirasi pertumbuhan $\left(R_{g}\right)$ dan respirasi pemeliharaan $\left(R_{m}\right)$ yang dihitung berdasarkan suhu udara dan massa masing-masing organ. Pertumbuhan masing-masing organ tanaman dan yang hilang melalui respirasi sebagai berikut :

\section{$d W_{x}=\eta_{x} B_{a} \cdot R_{g} R_{m} \eta_{x}\left(1-K_{g}\right) B_{a}-K_{m} W_{x} Q_{10}$}

Dimana:

$Q_{10}=2^{(T-20) / 10}$

$\mathrm{dW}_{\mathrm{x}}=$ penambahan massa organ $\mathrm{x}\left(\mathrm{kg} \mathrm{ha}^{-1} \mathrm{~d}^{-1}\right)$

$\mathrm{Rm}=$ respirasi pemeliharaan $\left(\mathrm{kg} \mathrm{ha}^{-1} \mathrm{~d}^{-1}\right)$

$\eta_{\mathrm{x}}=$ proporsi biomassa yang dialokasikan ke organ $\mathrm{x}$ (daun, batang akar dan biji)

$\mathrm{k}_{\mathrm{m}}=$ koefisien respirasi pemeliharaan

$k_{g}=$ koefisien respirasi pertumbuhan

$\mathrm{W}_{\mathrm{x}}=$ massa organ $\mathrm{x}\left(\mathrm{kg} \mathrm{ha}^{-1}\right)$

Tahap fenologi adalah faktor yang mempengaruhi pembagian asimilat pada organorgan vegetatif (daun, batang dan akar) selama kecambah muncul sampai pembungaan. Pada awal pertumbuhan, produksi biomassa hanya dialokasikan ke daun, batang dan akar dengan alokasi terbanyak pada daun. Sampai pembungaan. Alokasi biomassa ke daun dan akar berkurang sedangkan alokasi ke batang bertambah dengan fase perkembangan tanaman. setelah fase pembungaan, seluruh produksi biomassa dialokasikan ke biji. Berikut adalah parameter yang di gunakan untuk menghitung alokasi biomassa ke masing-masing organ.

\section{Indeks Luas Daun (ILD)}

ILD dihitung sebagai fungsi laju pertumbuhan daun harian (dw1) dan konsentrasi nitrogen daun. Persamaan indeks luas daun dapat dihitung dengan persamaan berikut :

$$
\begin{aligned}
\text { DILD } & =\left\{\left[\text { Nact }_{1}\right] \mathrm{dw} 1 / 20\right\} 10^{2}, \mathrm{dw} 1>0 \\
& =\left\{\left[\text { Nact }_{1} \mathrm{dw} 1 / \mathrm{s} \ln \right\} 10^{2}, \mathrm{dw}_{1} \leq 0\right.
\end{aligned}
$$

Dimana:

$$
\begin{aligned}
& \mathrm{dw}_{1}=\text { pertumbuhan daun }\left(\mathrm{kg} \mathrm{ha}^{-1} \mathrm{~d}^{-1}\right) \\
& \mathrm{Nact}_{1}=\text { konsentrasi nitrogen daun }(\%) \\
& \operatorname{sln}=\text { nitrogen daun spesifik }
\end{aligned}
$$

\section{Pengambilan Nitrogen}

Akar mengambil nitrogen awalnya dari lapisan permukaan dan kemudian pada lapisan terbawah didalam zona perakaran sampai kebutuhan tanaman terpenuhi.

Pada masing-masing lapisan, pengambilan nitrogen dilakukan dengan aliran massa dan pengambilan aktif. Aliran massa dihitung sebagai hasil dari aliran air ke akar $\{\operatorname{Tr}(1)\}$ dan konsentrasi nitrogen tanah dan nitrat $\left\{\mathrm{NO}_{3 c}(1)\right\}$.

$$
\operatorname{Nup}_{m}(1)=T_{r}(1) \mathrm{NO}_{3 c}(1)
$$

semua lapisan $1, \mathrm{NO}_{3 \mathrm{c}}(1)$ dihitung dari rasio nitrogen tersedia $\left\{\mathrm{NO}_{3}(1)\right\}$ dan kadar air (1).

$\mathrm{NO}_{3 \mathrm{c}}(1)=\mathrm{NO}_{3}(1) / \phi(1)$

Pengambilan aktif dihitung dengan persamaan Michaelis-Menten

$$
\begin{aligned}
& \operatorname{Nup}_{\mathrm{at}}(1)=\mathrm{W}_{\mathrm{r}}(1) \mathrm{t}_{\mathrm{n}} \mathrm{NO}_{3 \mathrm{c}}(1) /\left[\mathrm{k}_{\mathrm{m}}+\mathrm{NO}_{3 \mathrm{c}}(1)\right] \\
& \text { Dimana: } \\
& \mathrm{W}_{\mathrm{r}}(1)=\text { bobot akar di dalam lapisan } 1\left(\mathrm{~kg} \mathrm{ha}^{-1}\right) \\
& t_{n} \quad=\text { pengambilan nitrogen per unit bobot kering } \\
& \operatorname{akar}\left(\mathrm{kg} \mathrm{N} \mathrm{kg}^{-1} \mathrm{~d}^{-1}\right) \\
& \mathrm{km}=\operatorname{konsentrasi~} 1 / 2 \text { jenuh }\left(\mathrm{kg} \mathrm{N} \mathrm{ha}^{-1} \mathrm{~mm}^{-1}\right)
\end{aligned}
$$

\section{Mobilisasi Dan Pembagian Nitrogen}

Daun dan batang memiliki nitrogen struktural dan labil. Selama pelayuan nitrogen labil dimobilisasi antara organ-organ, sementara nitrogen struktural didalam jaringan-jaringan yang mati. Pelayuan dari daun dan batang memobilisasi nitrogen ( $\left.\mathrm{dN}_{\text {moby }}\right)$ sebagai hasil dari laju pelayuan $\left(D_{\gamma}\right)$ dan konsentrasi nitrogen $\left[\right.$ Nact $\left._{\gamma}\right)$ di atas suatu konsentrasi minimum $\left(\mathrm{N}_{\mathrm{mim}}\right)$ ditulis sebagai :

$$
\mathrm{dN}_{\text {moby }} \mathrm{D}_{\gamma}\left[\mathrm{Nact}_{\gamma}\right]-\left[\mathrm{N}_{\mathrm{mln}}\right] 10^{-2}
$$

Selama pengisian biji, nitrogen dimobilisasi dari daun ke batang. Kebutuhan nitrogen dipengaruhi oleh bobot biji $(\mathrm{Wg})$, konsentrasi nitrogen actual [Nact [an $_{\text {k }}$ konsentrasi maksimum. $\left[\mathrm{N}_{\text {maxg }}\right]=3 \%$, yang di tulis sebagai :

$\mathrm{Ndem}_{g}=\mathrm{Wg}\left\{3-\left[\mathrm{Nact}_{g}\right]\right\} 1^{-2}$ 


\section{Nitrogen Tanah}

Laju ammonifikasi pada masing-masing lapisan dihitung sebagai fungsi dari nitrogen organik, kadar air tanah dan temperatur $\left(Q_{10}=2^{(T-10) / 20}\right)$ yang mengikuti persamaan :

$\mathrm{dNH} 4(1)=Q_{10} k_{a m} o_{n}(1) \theta(1) \geq \theta_{w p}(1)=\theta, \theta(1)<$ $\theta_{\mathrm{wp}}(1)$.

Dimana:

$\mathrm{O}_{\mathrm{n}}=$ nitrogen organik di dalam lapisan $(\mathrm{kg}$ ha-1).

$\mathrm{k}_{\mathrm{am}}=$ laju konstan, yang memiliki nilai $9610^{-6} \mathrm{~d}^{-1}$ (Rogi, 1996).

Semua lapisan laju nitrifikasi potensial $\left(\mathrm{dNO}_{3 p}(1)\right)$ tergantung dari tersedianya $\mathrm{NH}_{4}\{\mathrm{NH} 4(1)\}$.

$\mathrm{dNO}_{3 \mathrm{P}}(1)=\mathrm{knlt}_{\mathrm{nlt}} \mathrm{NH}_{4}(1)$
Dimana:

$\mathrm{K}_{\text {nlt }}=$ konstanta laju nitrifikasi $\left(0,05 \mathrm{~d}^{-1}\right)$

Lamanya transformasi $\mathrm{NH}_{4}$ ke $\mathrm{NO}_{3}$ antara 14-19 hari, tergantung dari tipe dan kedalaman tanah.

Laju nitifikasi aktual $\left\{\mathrm{dNO}_{3 a}(1)\right\}$ dipengaruhi kelengasan tanah $\{\mathrm{fe}(1)\}$, temperatur (Q10) dan $\mathrm{pH}$ $\{\mathrm{fpH}(1)\}$, persamaannya adalah sebagai berikut :

$d \mathrm{NO}_{3 \mathrm{a}}(1)=\mathrm{Q}_{10} d \mathrm{NO}_{3 \mathrm{p}}(1) \max \left\{\mathrm{f}_{\theta}(1), \mathrm{F}_{\mathrm{pH}}(1)\right\}$,

Dimana:

$f_{\theta}(1)=0,038+1,02 \theta(1) / \theta_{\text {fc }}(1)$

$f_{p H}(1)=$ laju nitrifikasi relatif $(0-1)$ didalam $\mathrm{pH}$ mempunyai rentang 5-8.

\section{Pencucian (Leaching)}

Pelepasan nitrogen dari masing-masing lapisan $\left(\mathrm{L}_{\mathrm{NO} 3}(1)\right)$ dengan air yang diperkolasi $(\mathrm{Pc}(1)$ yang ditulis sebagai :

$\left(\mathrm{L}_{\mathrm{NO} 3}(1)\right)=\mathrm{Pc}(1) \mathrm{NO}_{3}(1) / \phi_{\mathrm{rc}}(1)+\mathrm{Pc}(1)$

\section{HASIL DAN PEMBAHASAN}

\section{Biomassa Akar}

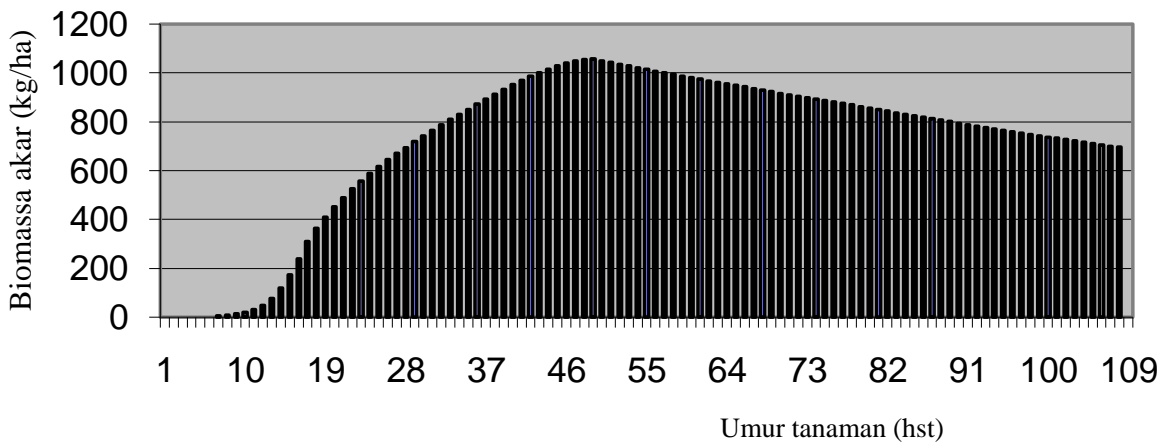

Gambar 1. Model Simulasi Biomassa Akar

(Figure 1. Root Biomass Simulation Model)

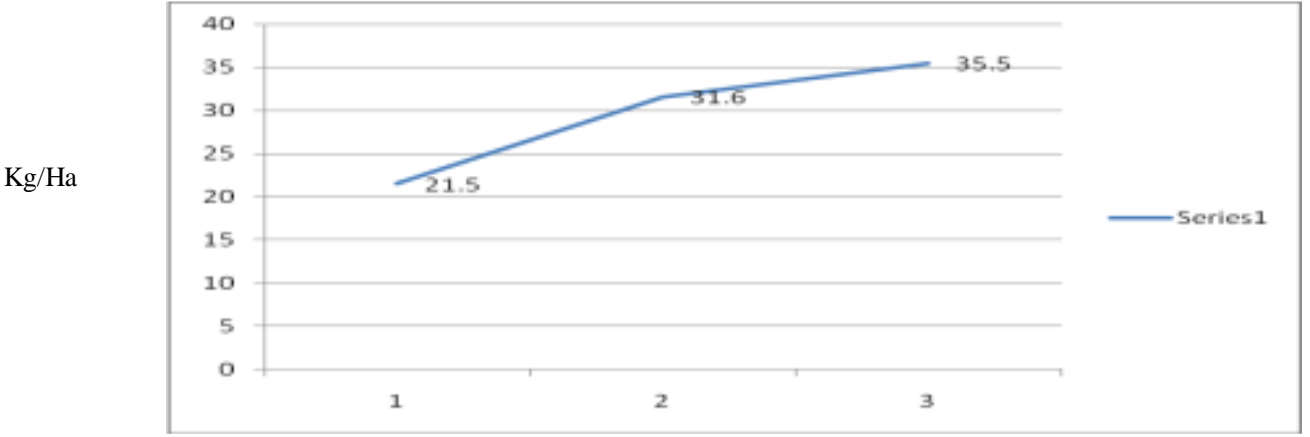

Pengamatan

Gambar 2. Model Biomassa Akar Tanpa Pemupukan (N0) Hasil Pengukuran Lapang

(Figure 2. Root Biomass Model Without Fertilizing (NO) the Field Measurement Results) 


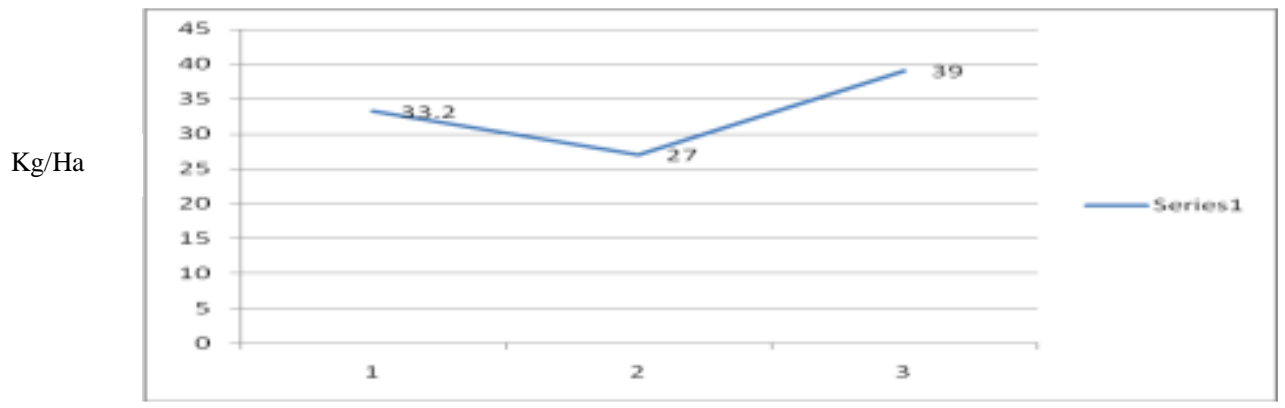

Pengamatan

Gambar 3. Model Biomassa Akar Pada taraf Pemupukan 46 kg N/ha (N1) Hasil Pengukuran Lapang (Figure 3. Model of Root Biomass at the Level of Fertilization $46 \mathrm{~kg}$ N/ha (N1) of Field Measurement Results)

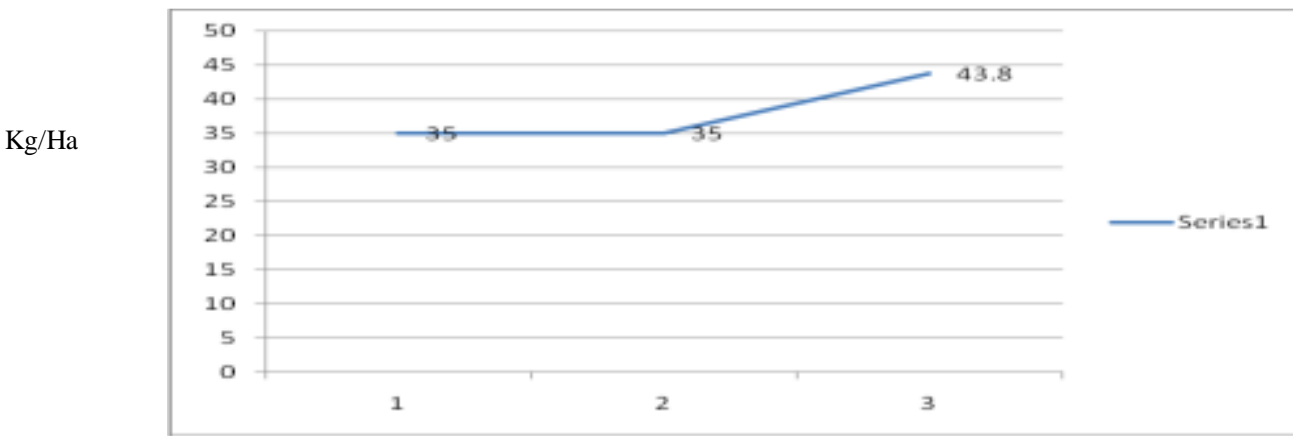

Pengamatan

Gambar 4. Model Biomassa Akar Pada taraf Pemupukan 92 kg N/ha (N2) Hasil Pengukuran Lapang (Figure 4. Model of Root Biomass at the Level of Fertilization $92 \mathrm{~kg} \mathrm{~N} / \mathrm{ha}$ (N2) of Field Measurement Results)

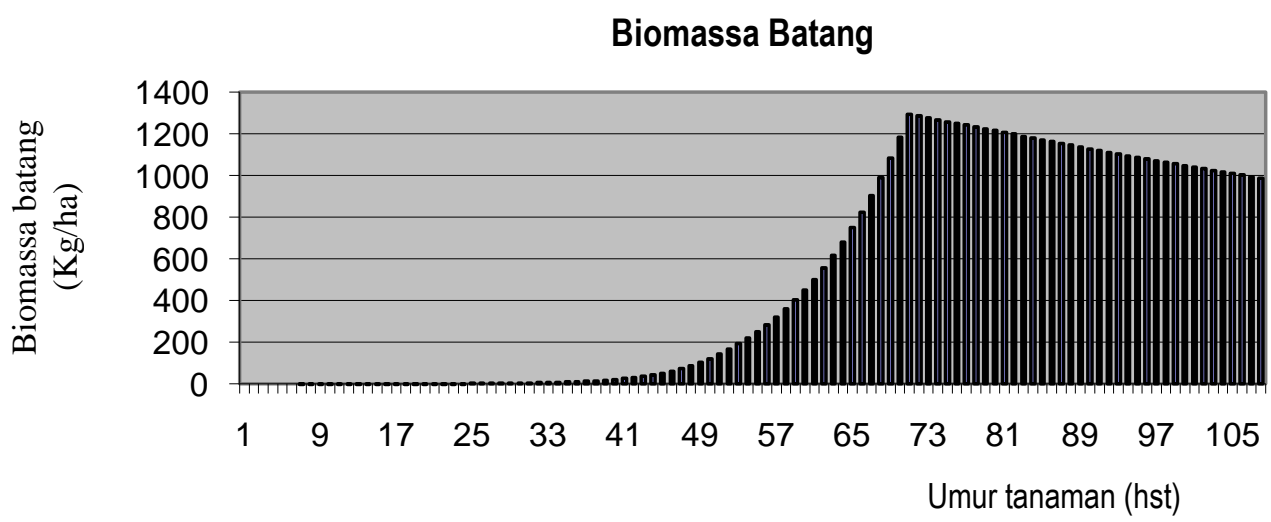

Gambar 5. Model Mensimulasi Aliran Biomassa Hasil Fotosintesis ke Organ Batang

(Figure 5. The Model Simulates the Flow of Biomass to the Organs of Photosynthesis Trunk)

Model simulasi pertumbuhan biomassa akar menggambarkan pada umur tanam 49 hari setelah tanam merupakan titik optimum biomassa akar yaitu $1050 \mathrm{~kg} / \mathrm{ha}$, selanjutnya kecenderungan menurun hingga matang fisiologis. Pada fase emergence sistem perakaran relatif belum berkembang, akar primer bercabang dari nodus pertama dibawah tanah. Produksi biomassa ke organ akar mendapat alokasi terbanyak setelah daun dan batang sampai pada fase inisiasi bunga alokasi biomassa akar berkurang. Nitrogen memegang peranan penting dalam proses biokimia tanaman, yaitu sebagi penyusun enzim, klorofil, asam nukleat, dinding sel dan berbagai komponen sel (Salisbury \& Ross, 1985).

Gambar 2 menunjukkan model biomassa akar tanpa pemupukan (NO) hasil pengukuran lapang yang cenderung terjadi kenaikkan mulai 
pada pengamatan $1(21.5 \mathrm{~kg} / \mathrm{ha})$, pengamatan ke 2 $(31.6 \mathrm{~kg} / \mathrm{ha})$, dan pengamatan $\mathrm{ke} 3(35.5 \mathrm{~kg} / \mathrm{ha})$. Tampilan gambar 3 model biomassa akar pada taraf pemupukan $46 \mathrm{~kg} \mathrm{~N} / \mathrm{ha}$ (N1) hasil pengukuran lapang menunjukkan kenaikkan pada pengamatan ke 3 dengan total produksi boimassa $39 \mathrm{~kg} / \mathrm{ha}$. Pada gambar 4 tampilan model biomassa akar pada taraf pemupukan $92 \mathrm{~kg} \mathrm{~N} / \mathrm{ha}$ (N2) hasil pengukuran lapang menunjukkan kenaikkan pada pengamatan ke 3 dengan total produksi biomassa $43.8 \mathrm{~kg} / \mathrm{ha}$. Hasil penelitian lapang ke 3 perlakuan pemupukan nitrogen terhadap biomassa akar menunjukkan bahwa pemupukan nitrogen dengan taraf $92 \mathrm{~kg} / \mathrm{ha}$ menghasilkan produksi tertinggi yaitu $43.8 \mathrm{~kg} / \mathrm{ha}$. Hal ini disebabkan nitrogen berperan dalam proses pertumbuhan vegetatif dan sangat berpengaruh terhadap pembentukan akar tanaman (Salisbury and Ross, 1985).

Model simulasi pertumbuhan biomassa akar menggambarkan pada umur tanam 49 hari setelah tanam merupakan titik optimum biomassa akar yaitu $240 \mathrm{~kg} / \mathrm{ha}$, selanjutnya kecenderungan menurun hingga matang fisiologis. Pada fase emergence sitem perakaran relatif belum berkembang, akar primer bercabang dari nodus pertama dibawah tanah. Produksi biomassa ke organ akar mendapat alokasi terbanyak setelah daun dan batang sampai pada fase inisiasi bunga alokasi biomassa akar berkurang (Rogi, 1996). Hasil simulasi model biomassa batang memperlihatkan bahwa pada umur tanam 70 hst alokasi proporsi fotosintesis mencapai angka tertinggi yaitu $1300 \mathrm{~kg} / \mathrm{ha}$ selanjutnya terjadi penurunan akibat remobilisasi asimilat ke organ lain tanaman. Remobilisasi asimilat dari batang digunakan untuk memelihara kekuatan batang agar tahan terhadap kerebahan (Milthorpe and Moorby, 2001). Berkurangnnya asimilat pada batang dapat berarti mengurangi resistensi terhadap kerebahan (Heard, 2004). Hubungan antara biomassa batang yang tinggi dengan ukuran diameter batang yang besar akan diikuti oleh pembentukan akar yang semakin banyak untuk mendukung proses penyerapan hara dan memperkokoh tanaman.

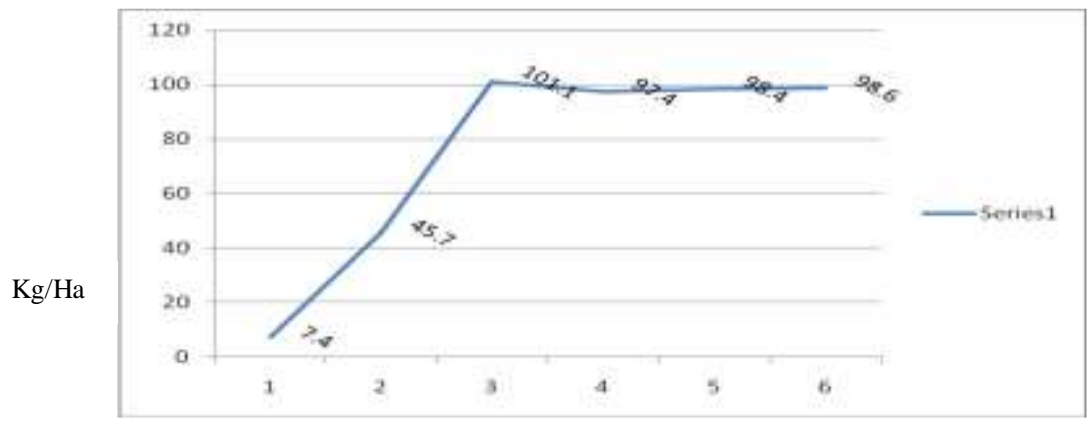

Pengamatan

Gambar 6. Model Biomassa Batang Tanpa Pemupukan (N0) Hasil Pengukuran Lapang

(Figure 6. Steem Biomass Model Without Fertilizing (NO) the Field Measurement Results)

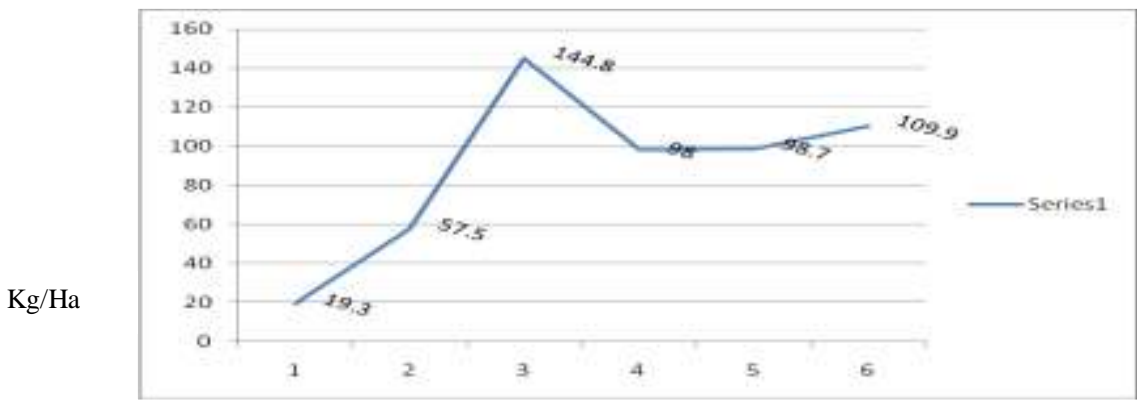

Pengamatan

Gambar 7. Model Biomassa Batang Pada Taraf Pemupukan 46 kg N/ha (N1) Hasil Pengukuran Lapang

(Figure 7. Model of Steem Biomass at the Level of Fertilization $46 \mathrm{~kg}$ N/ha (N1) of Field Measurement Results) 


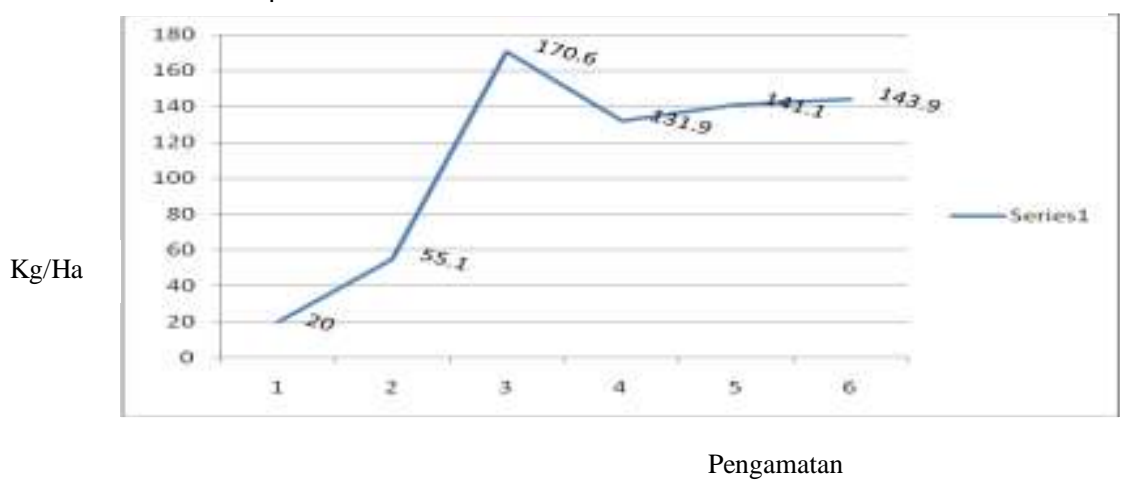

Gambar 8. Model Biomassa Batang Pada Taraf Pemupukan 92 kg N/ha (N2) Hasil Pengukuran Lapang (Figure 8. Model of Steem Biomass at the Level of Fertilization $92 \mathrm{~kg} \mathrm{~N} / \mathrm{ha}$ (N2) of Field Measurement Results)

Tampilan Gambar 6 model biomassa batang tanpa pemupukan (N0) hasil pengukuran lapang menunjukkan kenaikkan biomassa yang sangat cepat hingga pada pengamatan ke 3 dengan nilai produksi $100 \mathrm{~kg} / \mathrm{ha}$, selanjutnya mengalami penurunan hingga pengamatan ke $6(98.6 \mathrm{~kg} / \mathrm{ha})$. Gambar 7 tampilan model biomassa batang pada taraf pemupukan $46 \mathrm{~kg} \mathrm{~N} / \mathrm{ha}$ (N1) hasil pengukuran lapang memperlihatkan kenaikkan optimum pada pengamatan ke 3 dengan total produksi 144.8 $\mathrm{kg} / \mathrm{ha}$, cenderung turun pada pengamatan $\mathrm{ke} 4(98$ $\mathrm{kg} / \mathrm{ha}$ ) dan terjadi kenaikkan pada pengamatan ke 6 (109.9 kg/ha). Gambar 8 tampilan model biomassa batang pada taraf pemupukan $92 \mathrm{~kg}$ $\mathrm{N} / \mathrm{ha}$ (N2) hasil pengukuran lapang menunjukkan kenaikkan hingga $170.6 \mathrm{~kg} / \mathrm{ha}$ pada pengamatan ke 3 , cenderung turun pada pengamatan ke 4 (131.9), mengalami kenaikkan hingga pada pengamatan ke 6 dengan total produksi 143.9 $\mathrm{kg} / \mathrm{ha}$. Perbandingan produksi ke 3 perlakuan taraf pemupukan diatas memperlihatkan bahwa pencapaian total biomassa tertinggi dihasilkan oleh pemupukan dengan taraf nitrogen $92 \mathrm{~kg} / \mathrm{ha}$. Kenaikkan total produksi biomassa batang pada pengamatan ke 3 dari semua perlakuan disebabkan pada masa tersebut pertumbuhan tanaman mengalami masa periode vegetatif aktif, pertumbuhan dan pertambahan jumlah sel menyangkut metabolisme tanaman terhadap serapan hara termasuk nitrogen sebagai salah satu komponen sel dan pembentukan makromolekul (Salisbury and Ross, 1985).

Penurunan produksi terjadi akibat remobilisasi asimilat ke organ lain tanaman (Heard, 2004). Remobilisasi asimilat dari batang digunakan untuk memelihara kekuatan batang agar tahan terhadap kerebahan berkurangnnya asimilat pada batang dapat berarti mengurangi resistensi terhadap kerebahan. Hubungan antara biomassa batang yang tinggi dengan ukuran diameter batang yang besar akan diikuti oleh pembentukan akar yang semakin banyak untuk mendukung proses penyerapan hara dan memperkokoh tanaman.

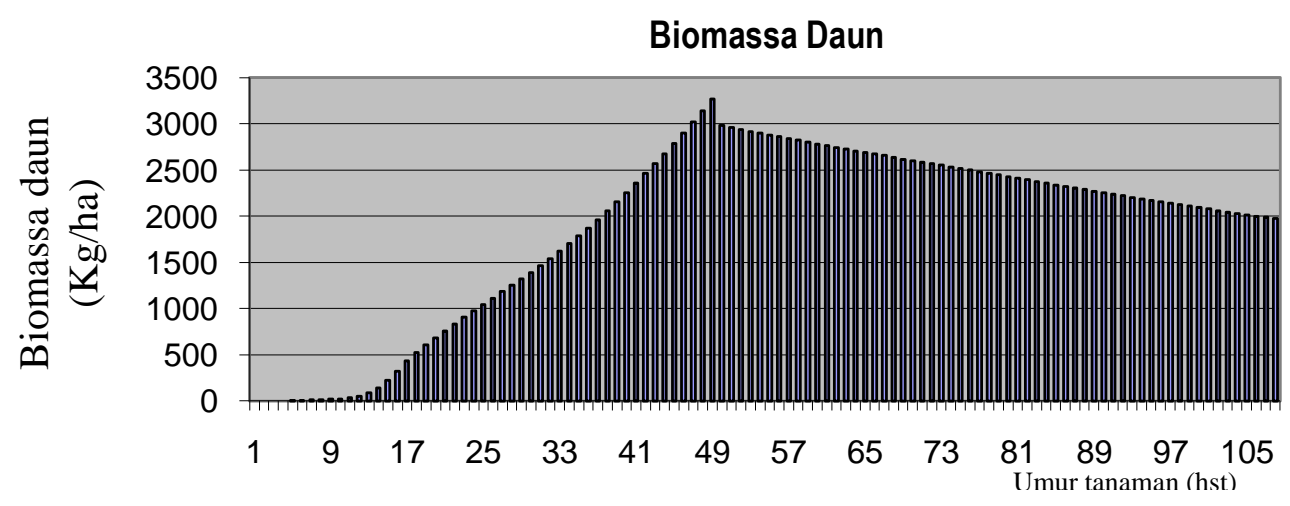

Gambar 9. Model Biomassa Daun Hasil Simulasi

(Figure 9. Leaf biomass model simulation results). 


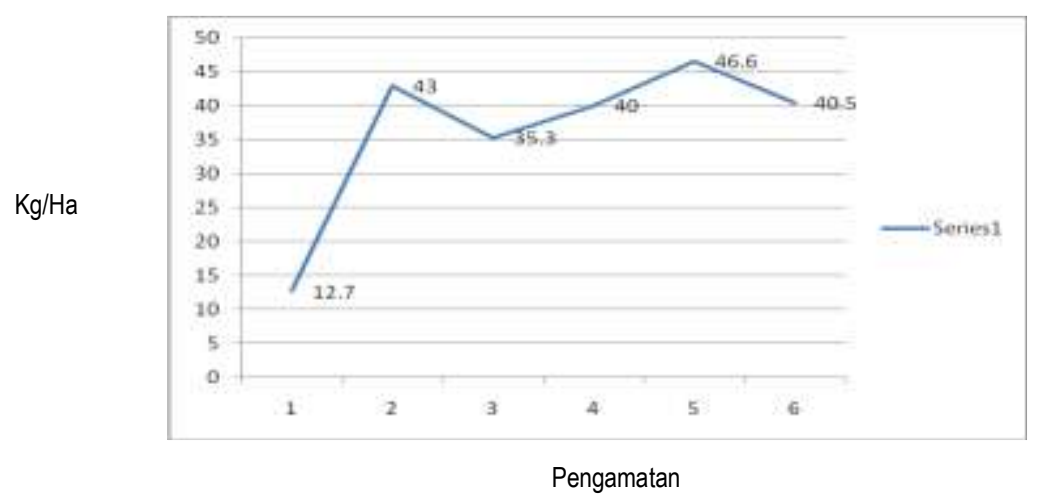

Gambar 10. Biomassa Daun Tanpa Pemupukan (No) Hasil Pengukuran Lapang

(Figure 10. Leaf Biomass Model Without Fertilizing (NO) the Field Measurement Results)

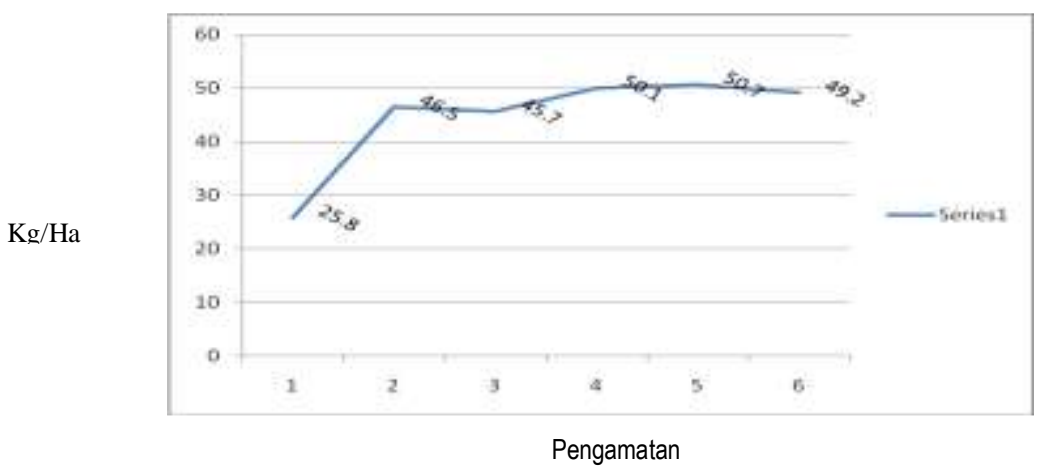

Gambar 11. Biomassa Daun Pada Pemupukan 46 kg N/ha (N1) Hasil Pengukuran Lapang

(Figure 11. Model of Leaf Biomass at the Level of Fertilization $46 \mathrm{~kg}$ N/ha (N1) of Field Measurement Results)

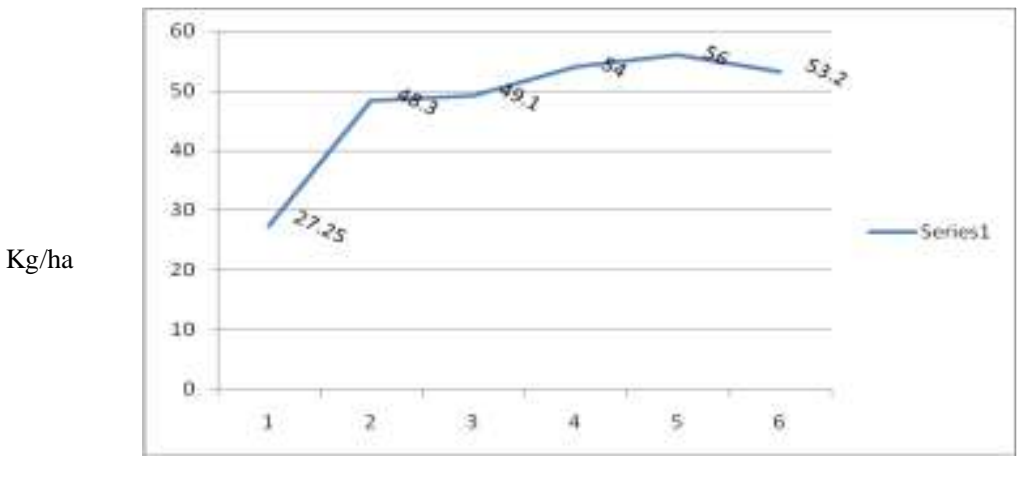

Pengamatan

Gambar 12. Biomassa Daun Pada Pemupukan 92 kg N/ha (N2) Hasil Pengukuran Lapang

(Figure 12. Model of Leaf Biomass at the Level of Fertilization $92 \mathrm{~kg} \mathrm{N/ha}$ (N2) of Field Measurement Results)

Gambar 12 tampilan biomassa daun tanpa pemupukan (No) hasil pengukuran lapang memperlihatkan hasil pengamatan 1 yaitu 12.7 $\mathrm{kg} / \mathrm{ha}$ dan hasil tertinggi dicapai pada pengamatan ke 5 (46.6 kg/ha). Gambar 10 tampilan biomassa daun pada pemupukan $46 \mathrm{~kg} \mathrm{~N} / \mathrm{ha}$ (N1) hasil pengukuran lapang menunjukkan hasil tertinggi dicapai pada pengamatan ke $5(50.7 \mathrm{~kg} / \mathrm{ha})$ dan hasil pengamatan pada pertumbuhan awal yaitu
$25.8 \mathrm{~kg} / \mathrm{ha}$. Gambar 11 tampilan biomassa daun pada pemupukan $92 \mathrm{~kg} \mathrm{~N} / \mathrm{ha}$ (N2) hasil pengukuran lapang memberi hasil tertinggi dengan total produksi $53.2 \mathrm{~kg} / \mathrm{ha}$ dan hasil pertumbuhan awal $27.2 \mathrm{~kg} / \mathrm{ha}$. Nilai-nilai produksi dari tiga perlakuan diatas menunjukkan bahwa hasil produksi biomassa daun tertinggi dihasilkan pada taraf pemupukan nitrogen $92 \mathrm{~kg} / \mathrm{ha}$. 


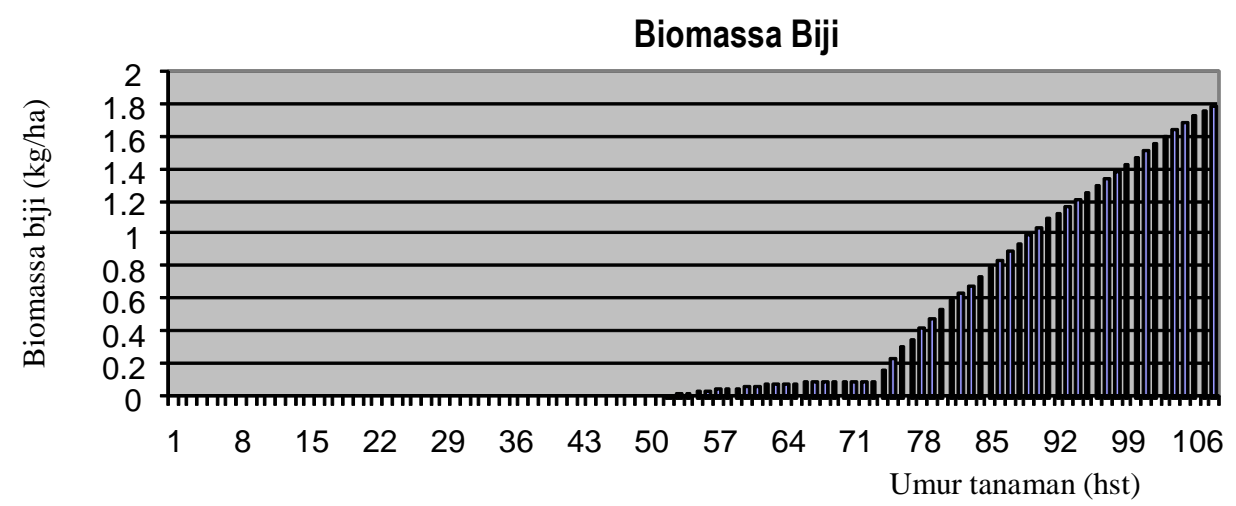

Gambar 13. Model Mensimulasi Aliran Biomassa Hasil Fotosintetis ke Biji

(Figure 13. The Model Simulates the Flow of Biomass to the Seeds of Photosynthesis)

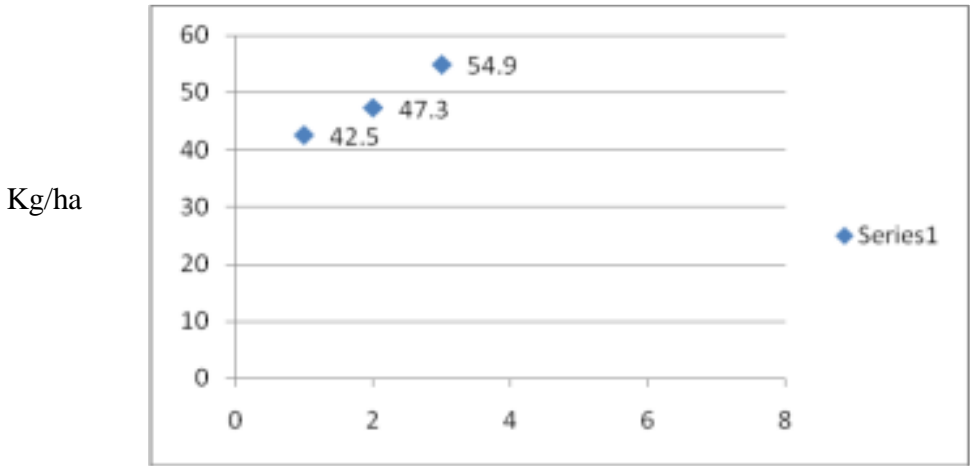

pengamatan

Gambar 14 . Biomassa Biji Hasil Pengukuran Lapang

(Figure 14. Biomass Seed Field Measurement results)

Optimalisasi proporsi biomassa yang dialokasikan ke daun sampai pada fase pembungaan yaitu 49 hari setelah tanam dengan bobot $3000 \mathrm{~kg} / \mathrm{ha}$. Biomassa daun yang menurun setelah fase inisiasi pembungaan disebabkan oleh makin banyak biomassa yang dialokasikan ke batang. Gambar 9 tampilan model memperlihatkan pada awal pertumbuhan produksi biomassa hanya dialokasikan ke daun, batang dan akar dengan alokasi terbanyak pada daun. Setelah fase pembungaan alokasi biomassa hasil fotosintetis ke daun dan akar berkurang sedangkan alokasi ke batang meningkat. Pemupukan nitrogen akan mempercepat perkembangan tajuk, dan mempunyai korelasi positif dengan banyaknya radiasi yang akan diterima oleh permukaan tajuk tanaman (Jones, 1983). Peningkatan penerimaan radiasi surya oleh tajuk bersifat eksponensial serta apabila tanaman dengan To (waktu hilang) yang singkat, maka akan mengembangkan tajuk lebih awal sehingga penerimaan radiasi menjadi lebih besar (Paruntu dan Palenewen, 1990). Gambar 13 tampilan model biomassa biji menunjukkan bahwa setelah fase anthesis yaitu $73 \mathrm{hst}$, fase pengiriman biji mulai berlangsung hingga matang fisiologis pada 105 hari setelah tanam dengan total biji 4500 $\mathrm{kg} / \mathrm{ha}$. Translokasi asimilat pada pengisian biji berasal dari daun-daun bagian atas yaitu sebesar 89 persen (Paulus, 1992).

Gambar 14 tampilan hasil pengukuran lapang biomassa biji memperlihatkan hasil tertinggi yaitu $54.9 \mathrm{~kg} / \mathrm{ha}$. Biomassa biji ditentukan oleh akumulasi asimilat pada biji selama proses pengisian biji. Pada saat pembungaan, tanaman menyerap nitrogen sebesar 50 persen dari seluruh kebutuhan nitrogen total tanaman (Paulus, 1992). Fotosintat yang terakumulasi pada biji dapat berasal dari aktivitas fotosintesis yang berlangsung pada saat pengisian biji atau dari remobilisasi asimilat yang sudah diakumulasikan dari organ lain tanaman (Salisbury and Ross, 1985). 


\section{KESIMPULAN DAN SARAN}

\section{Kesimpulan}

Berdasarkan hasil penelitian yang dilakukan dapat disimpulkan sebagai berikut :

1) Simulasi model biomassa akar tertinggi yaitu $1050 \mathrm{~kg} / \mathrm{ha}$ pada umur tanam 49 hari setelah tanam. 2) Produksi biomassa akar tertinggi dihasilkan pada taraf pemupukan nitrogen $92 \mathrm{~kg} / \mathrm{ha}$ dengan total produksi $43.8 \mathrm{~kg} / \mathrm{ha}$. 3). Biomassa batang hasil pengukuran lapang tertinggi 170.6 $\mathrm{kg} / \mathrm{ha}$ pada taraf pemupukan $92 \mathrm{~kg} \mathrm{~N} / \mathrm{ha}$. 4) Simulasi model biomassa batang pada umur tanam 70 hst menghasilkan $1300 \mathrm{~kg} / \mathrm{ha}$. 5). Produksi biomassa daun tertinggi dihasilkan pada taraf pemupukan nitrogen $92 \mathrm{~kg} / \mathrm{ha}$ dengan total produksi $53.2 \mathrm{~kg} / \mathrm{ha}$. 6). Simulasi biomassa daun yaitu 49 hari setelah tanam dengan bobot 3000 $\mathrm{kg} / \mathrm{ha}$. 7). Produksi biomassa biji tertinggi hasil pengukuran lapang yaitu $54.9 \mathrm{~kg} / \mathrm{ha}$ pada taraf pemupukan $92 \mathrm{~kg} \mathrm{~N} / \mathrm{ha}$. 8). Simulasi biomassa biji pada 105 hari setelah tanam dengan total biji 4500 $\mathrm{kg} / \mathrm{ha}$ dan fase anthesis pada $73 \mathrm{hst}$.

\section{Saran}

Berdasarkan hasil penelitian yang dilakukan maka dapat disarankan penyusunan model simulasi biomassa perlu penambahan variabel pengamatan guna perbaikan model selanjutnya serta .penyusunan model simulasi biomassa dengan sinergitas unsur makro dan mikro

\section{DAFTAR PUSTAKA}

Anonim, 2007. Notulen Rapat Dewan Jagung Nasional. Jakarta (http.//www.produksi jagung/djn.htm) 2007. Produksi Jagung Meningkat Kurun Waktu Lima Tahun Terakhir. Warta Puslitbang. $\quad$ http://www.produksijagung/ index. htm)

Apriyantono, 2007. Seminar dan Ekspose Inovasi Teknologi Jagung Mendukung Revitalisasi Pertanian. Makassar. Puslitbang. (http.//www produksijagung/index.php.htm.) Engelstad, O. P. 1985. Fertilizer Technology And
Use.Third Edition. Soil Science Society Of America, Inc.

Engelstad, O. P. 1985. Fertilizer Technology And Use.Third Edition. Soil Science Society Of America, Inc. 2-354pp.

Handoko, 1996 Analisis Sistem dan Model Simulasi Komputer untuk Perencanaan Pertanian di Indonesia. IPB- Bogor.

Heard, J. 2004. Nutrient Uptake And Removal Patterns In High Yielding Manitoba Corn Manitoba Agriculture. (http://www.maize. corncob.htm).

Jones, H. G. 1983. Plants And Microclimate. A quantitative approach to environmental plant physiology. Cambridge University Press. 323p.

Milthorpe, F.L and Moorby, J. 2001. An Introdution To Crop Physiology. Melbourne.

Paulus, J. M. 1992. Pengaruh Pemupukan Nitrogen Dan Waktu Tanam Terhadap Pertumbuhan Dan Hasil Jagung (Zea mays L.) Di Antara Kelapa. Tesis Magister KPK IPB-UNSRAT Manado.

Paruntu, J, dan J. L. Palenewen. 1990. Analisis Tumbuh Dan Efisiensi Penggunaan Radiasi Pada Tanaman Jagung. Fakultas Pertanian Unsrat. Manado. 25p.

Runtunuwu, D. S. 1990. Tumpangsari Jagung dan Kedelai Di Bawah Naungan Kelapa Tua. Tesis Magister. KPK IPB-UNSRAT. Manado.

Rogi, J. E. X. 1996. Penyusunan Model Simulasi Dinamika Nitrogen Pertanaman Kelapa Sawit (Elaeis guineensis Jacq.) Di Unit Usaha Bekrie Provinsi Lampung. Disertasi Doktoral. IPB. Bogor

Salisbury, F.B and C.W Ross. 1985. Plant Physiology. Wardsworth Publ.Co. California.

Thorne, D. W. dan M. D. Thorne. 1979. Soil, Water, and Crop Production. The Avi Publishing Company, Inc. Connecticut. USA. 353pp

Walalangi, I. Th. 2007. Pemupukan Nitrogen dan Ketahanan Jagung Terhadap Kekeringan. Pidato Pengukuhan Guru Besar Tetap IImu Fisiologi Tumbuhan Fakultas Pertanian Unsrat. 